\title{
Ventricular ectopy after exercise and occult ischaemia in a patient with multiple risk factors for ischaemic heart disease and defective anginal warning system
}

\author{
Gian Piero Carboni, ${ }^{1}$ Pietro Sedati ${ }^{2}$
}

${ }^{1}$ Department of Nuclear Cardiology, Università Campus Bio-Medico, Rome, Italy ${ }^{2}$ Department of Radiology, Università Campus Bio-Medico, Roma, Italy

\section{Correspondence to}

Professor Gian Piero Carboni, g.carboni@unicampus.it
To cite: Carboni GP Sedati P. BMJ Case Reports Published online: [please include Day Month Year] doi:10.1136/bcr-2012007536

\section{DESCRIPTION}

In May 2012, a 73-year-old man presented with effort dyspnoea and chest discomfort, negative exercise test for ST depression and ventricular ectopy after exercise. He had a history of Sjögren's syndrome, diabetes, dyslipidemia, hypertension, chronic obstructive pulmonary disease and was under methotrexate treatment for rheumatoid arthritis. Such diseases imply a severe dysfunctional burden, tend to develop accelerated atherosclerosis, endothelial dysfunction and ischaemic heart disease (IHD). ${ }^{1}{ }^{2}$ A functional assessment was thus provided with an exercise/rest technetium-99 m tetrofosmin-gated single-photon emission cardiac tomography (G-SPECT). This test did not show perfusion defects; left ventricular function was normal (figure 1). At peak exercise, there was lack of ST-depression, but episodes of ventricular triplets were detected after exercise (figure 2). A cardiac tomography (CT) scan detected a severe stenosis in the middle portion of the left anterior descending (LAD) coronary artery (figure 3). An invasive coronary angiography revealed $90 \%$ stenosis of the LAD; therefore, a stent was implanted. Ventricular ectopy after exercise is associated with reactivation of parasympathetic activity and an increased risk of death. ${ }^{3}$ In the presence of a subocclusive LAD stenosis, the patient's exercise SPECT results should be thus
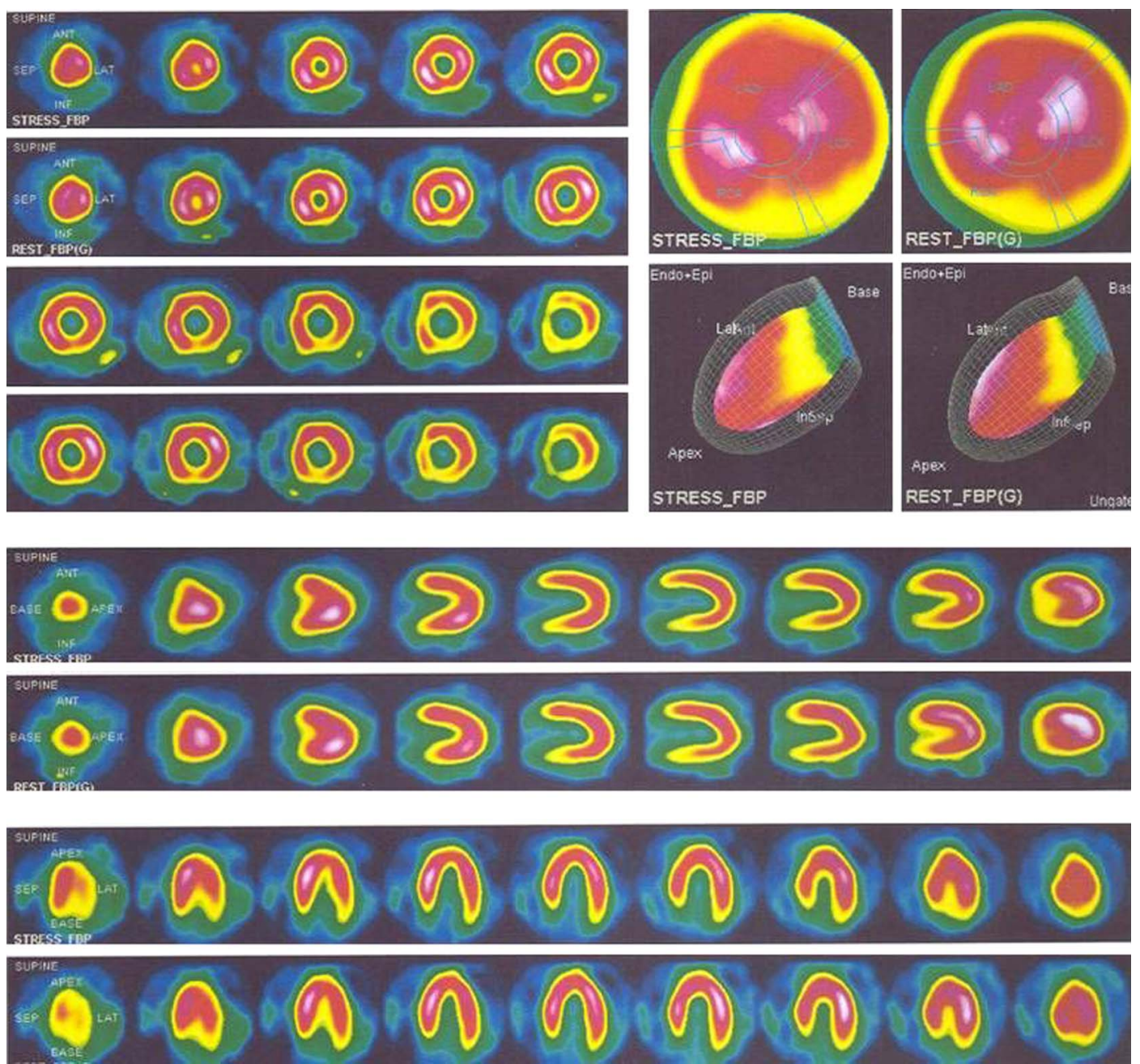

Figure 1 Exercise-gated /rest-gated single-photon emission cardiac tomography shows lack of significant perfusion defects and a normal left ventricular function. 
Figure 2 A run of ventricular triplets and an isolated ventricular ectopy during the exercise test recovery period. Heart rate (HR); beats per minute (bpm) and systolic blood pressure (SBP).
Peak exercise

100 Watts, HR = $144 \mathrm{bpm}, \mathrm{SBP}=210 \mathrm{mmHg}$

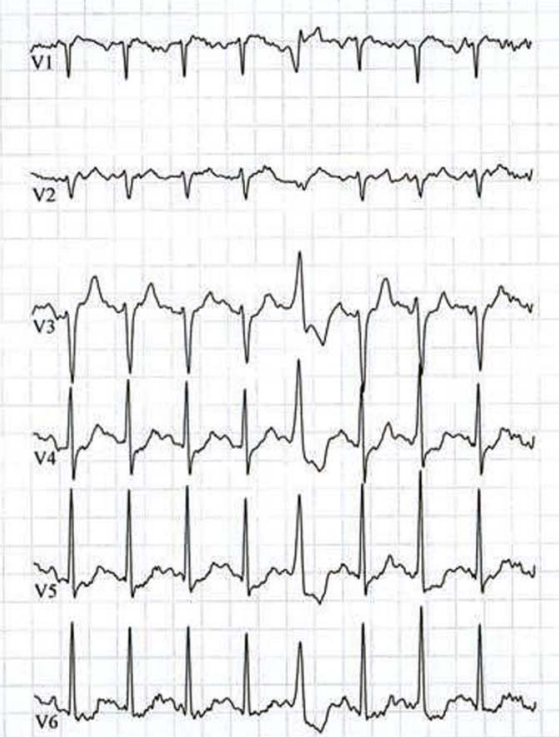

Recovery

$\mathrm{HR}=111, \mathrm{bpm} \mathrm{SBP}=160 \mathrm{mmHg}$
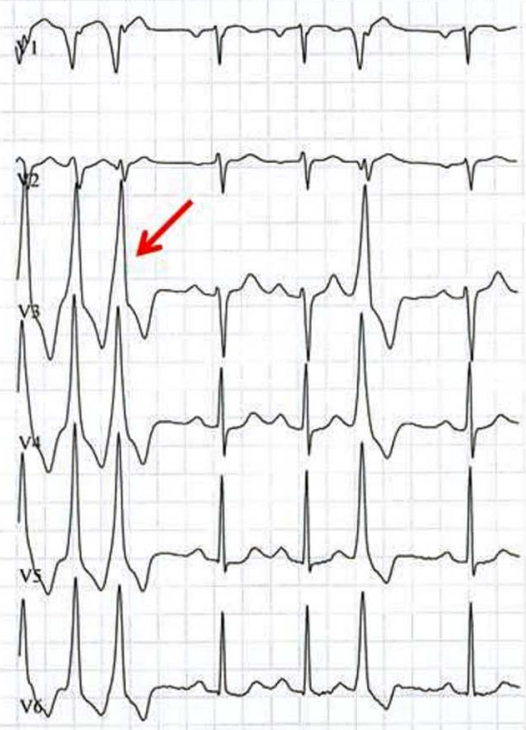

considered as false negative. Occult exercise-induced ischaemia and a reperfusion mechanism for postexercise ventricular ectopy cannot be ruled out. Reperfusion re-establishes slow conduction through depressed regions, permitting re-entrant pathways to form again, resulting in the re-emergence of ventricular arrhythmias. ${ }^{4}$ Cardiac CT may provide early-stage screening for occult IHD in patients with multiple risk factors for IHD and defective anginal warning system.

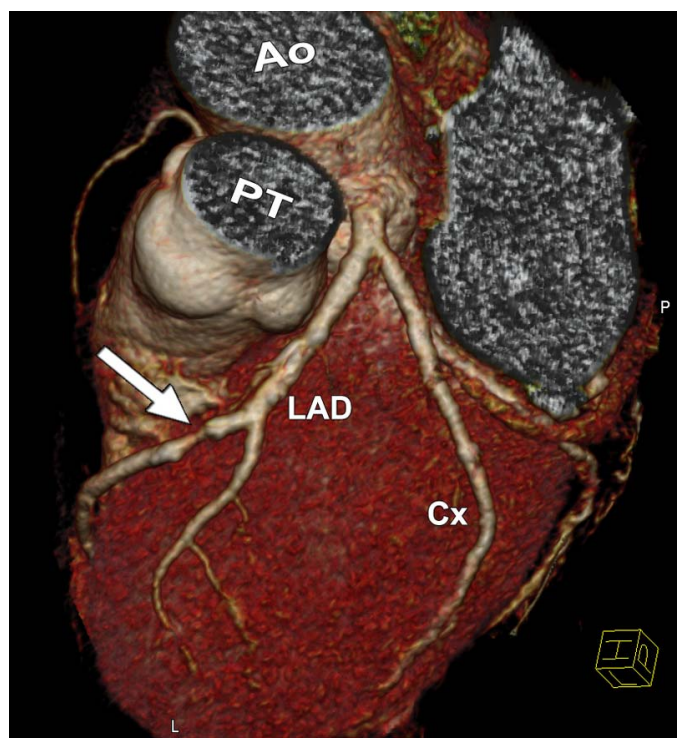

Figure 3 Volume-rendered cardiac CT images indicate a severe stenosis in the middle portion of the anterior descending (LAD) artery. Aorta(Ao), pulmonary trunk (PT) and left circumflex artery $(\mathrm{Cx})$.

\section{Learning points}

- Rheumatoid arthritis and other rheumatic diseases significantly increase the risk of atherosclerosis.

- Diabetes, rheumatoid arthritis and Sjögren's syndrome may lead to uncommon presentations of ischaemic heart disease.

- If pretest probability is high, negative test results should not stop investigations.

- Ventricular arrhythmias may be a sign of cardiac hypoperfusion even in a negative test.

Competing interests None.

Patient consent Obtained.

Provenance and peer review Not commissioned; externally peer reviewed.

\section{REFERENCES}

1 Mellana WM, Aronow WS, Palaniswamy C, et al. Rheumatoid arthritis: cardiovascular manifestations, pathogenesis, and therapy. Curr Pharm Des 2012;18:1450-6.

2 Inoue $H$, Kinoshita $K$, Sugiyama $M$, et al. Sudden death from ischaemic heart disease in a female patient with Sjögren syndrome: a case report. Med Sci Law 2008;48:261-5.

3 Frolkis JP, Pothier $\mathrm{CE}$, Blackstone $\mathrm{EH}$, et al. Frequent ventricular ectopy after exercise as a predictor of death. N Engl J Med 2003;348:781-90.

4 Murdock DK, Loeb JM, Euler DE, et al. Electrophysiology of coronary reperfusion. A mechanism for reperfusion arrhythmias. Circulation 1980;61:175-82. 
Copyright 2013 BMJ Publishing Group. All rights reserved. For permission to reuse any of this content visit http://group.bmj.com/group/rights-licensing/permissions.

BMJ Case Report Fellows may re-use this article for personal use and teaching without any further permission.

Become a Fellow of BMJ Case Reports today and you can:

- Submit as many cases as you like

- Enjoy fast sympathetic peer review and rapid publication of accepted articles

- Access all the published articles

- Re-use any of the published material for personal use and teaching without further permission

For information on Institutional Fellowships contact consortiasales@bmjgroup.com

Visit casereports.bmj.com for more articles like this and to become a Fellow 